\title{
The uptake of social security benefits among psychiatric day hospital patients
}

\author{
Daniel S. Allen, Registrar; and Renate West, Social Worker, Basingstoke District \\ Hospital, Psychiatric Division, Park Prewett, Basingstoke
}

A leader in the British Medical Journal (BMJ) last year (Marks, 1988) suggested that the uptake of social security benefits among mentally ill people is low. However, this statement was based on the only data the writer could find - a study of 37 patients conducted in Islington based on the old social security system, prior to April 1988 (Linney \& Boswell, 1987). Two weeks later, another BMJ leader (Marcovitch, 1988) bemoaned the fact that insufficient research had been conducted on the impact of changes in the social security system.

Our study looks at the uptake of benefits in day hospitals because of the implications this has as psychiatric care moves into the community. It does not address questions about the quality of life or financial hardship (either absolute or compared with pre-April 1988 levels).

\section{The study}

The first task was to design a structured questionnaire to be completed by the interviewer. Following field-testing this consisted of nine subsections: (1) personal details; (2) income and savings; (3) medical fitness to work; (4) home situation; (5) expenses; (6) debt; (7) benefits; (8) financial help; and (9) housing.

The questionnaire was designed to exclude people who were ineligible for benefits on the grounds either of having too large an amount of savings, or having some savings and being able to work. These people 'exited' after section 3 above.

The results were analysed by $\mathrm{RW}$ using available Department of Social Security (DSS) guidelines on eligibility for social security benefits. The initial judgement was whether an individual appeared entitled to claim for a given benefit. The completed forms were then scrutinised in order to see how the rest of the data fitted in with these findings.

\section{Findings}

Twenty-eight people from Basingstoke and 22 from Winchester took part in the survey ( 22 males and 28 females). Only six stated that they were capable of work (of these only two had actually got jobs - both part-time). Two people who lived with their parents had no income at all; 16 people had no savings, and 25 had under $£ 3000$.

Thirty-six people lived on benefits alone (including pensions). Seven people were not entitled to benefits through having too high savings and/or being able to work. Three people believed correctly that they were not entitled to any benefits (two were on full salary and one received a pension and her husband was on full salary). One person was claiming attendance allowance on her daughter's behalf, and three people were in the process of making a 'correct' application for benefit. Of those asked, $65 \%$ had obtained information about benefits from the DSS and only two found out from a social worker.

Twenty-four people were claiming all the benefits they were entitled to; however two people who believed they were not entitled to any benefit we judged able to claim for invalidity benefit (IB)/severe disablement allowance (SDA) in one case and invalid care allowance in the other.

Ten people, already in contact with the benefits system, were judged eligible to apply for another benefit. In seven cases this was housing benefit (HB) and in two of these they were also eligible for IB/ SDA. Of the remaining three people, one was eligible for IB/SDA and the other two for income support.

In only one case did we establish evidence of the DSS volunteering further information and that was when the person apparently received income support when he applied for sickness benefit because "it was worth $\mathrm{fl}$ more".

\section{Conclusions}

Probably the most significant finding in our study was that more than a quarter of the people already in contact with the social security system were entitled to claim for at least one further benefit. Only two people who were eligible for benefits were not in contact with the DSS already.

Over half the unclaimed benefits were for HB. We encountered no evidence that local authorities (who administer this benefit on behalf of the DSS) were informing people directly about it, nor that the DSS were promoting it when people applied for benefits other than income support. 
It was also interesting to note that, despite the presence of social workers in both day hospitals, only two respondents cited them as a source of information about benefits. This may be related to people's perception that they did not require further help, and perhaps too an assumption that the DSS would tell them if they were entitled to any other benefits.

At the moment there is no standard system within the DSS for screening those who apply for one benefit to see if they are entitled to another. Our study indicates that there is a need for this, and we are encouraged that the department itself, in a recent report, recommends a client-based, rather than a benefits-based, service (Moodie et al, 1988).

There are several schemes across the country, often involving the Citizens Advice Bureau, where advice agencies have been set up in psychiatric hospitals and units (Davis, 1988). It may be that the DSS itself should consider going out to psychiatric units once it has developed its client-based service.

\section{Acknowledgement}

We would like to thank the patients and staff of Park Clinic and Connaught House for their co-operation.

\section{References}

DAvis, A. (1988) Mental Health and Welfare RightsNetwork Directory. Social Administration Department, University of Birmingham.

LINNEY, J. \& BOSWELL, C. (1987) Social Security and Mental Illness. London: Islington People's Rights.

MARCOVITCH, H. (1988) Impact of changes in social security. British Medical Journal, 297, 1282-1283.

MARKS, B. E. (1988) Social security benefits for the mentally ill. British Medical Journal, 297, 1148.

MOOdie, M., Mizen, N., Heron, R. \& MACKAY, R. (1988) The Business of Service. The Report of the Regional Organisation Scrutiny. London: DHSS. p. 26, para. 61.2.

\section{Training Matters}

\section{Metanoia}

\section{Hugh Freeman, Editor, British Journal of Psychiatry}

Opportunities for training in psychotherapy have become more extensive in Britain over the last decade or so, though the increase - as always - has been seen mainly in London and its satellites. The diversity of these training organisations, most of which are outside the mainstreams of NHS and university courses, does not make it easy for their value to be assessed in conventional terms, as well as raising problematic issues about the interface between the public and private sectors.

One of the most interesting of the newer facilities is to be found in a converted Victorian house in Ealing.
Metanoia - a Greek word meaning transformation of mind or character - is the title of this psychotherapy training institute, established by a group of professionals who left South Africa for political reasons, some 13 years ago. On arrival here, they recreated in a Bayswater flat an idea that had begun in Johannesburg. The founder is a clinical psychologist with a background in psychotherapy and neurophysiology, and there are two other psychologists both with experience in education, as well as two medical/psychiatric consultants. All staff members have worked in psychiatric hospitals at some 